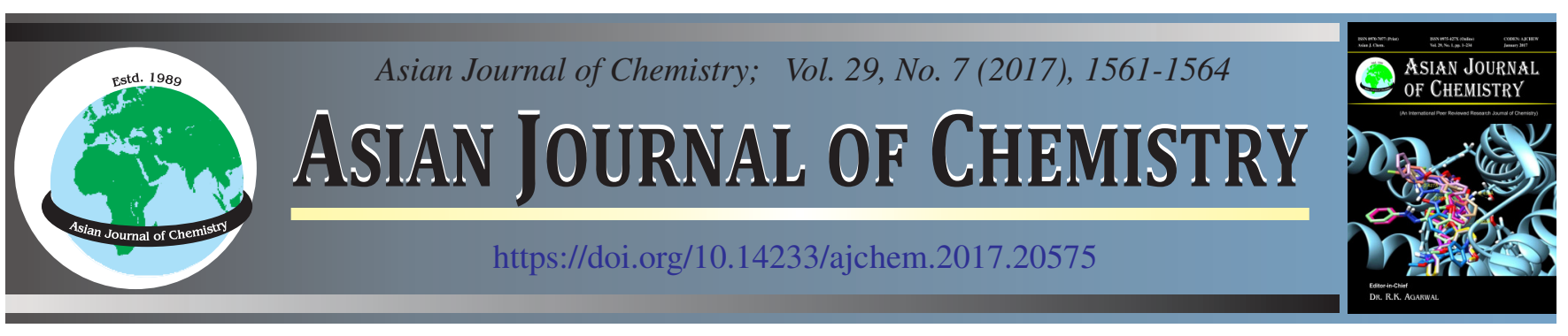

\title{
A Simple and Straightforward Synthesis of Cinnamic acids and Ylidene Malononitriles via Knoevenagel Condensation Employing DABCO as Catalyst
}

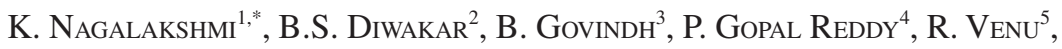 \\ I. Bhargavi ${ }^{1}$, T.J. Prasanna Devi ${ }^{1}$, Y.L.N. Murthy ${ }^{1}$ and V. Siddaiah ${ }^{1}$
}

\begin{abstract}
${ }^{1}$ Department of Organic Chemistry, Organic Research Labs, Andhra University, Visakhapatnam-530 003, India
${ }^{2}$ Department of Engineering Chemsitry, SRKR Engineering College (A), Bhimavaram-534 204, India

${ }^{3}$ Department of H\&S, Raghu Institute of Technology, Visakhapatnam-531 162, India

${ }^{4}$ Shilpa Medicare Limited, Raichur-584 135, India

${ }^{5}$ School of Engineering Science \& Technology, University of Hyderabad, Hyderabad-500 046, India

*Corresponding author: E-mail: nagalakshmi3083@gmail.com
\end{abstract}

\begin{abstract}
An efficient method for the synthesis of substituted cinnamic acid and ylidene malanonitriles is developed via Knoevenagel condensation of aromatic aldehydes with malonic acid and malononitrile in the presence of catalytic amounts of DABCO. This method has many advantages, such as mild reaction conditions, excellent yields, short reaction times and no furthur purification required.
\end{abstract}

Keywords: DABCO, Aromatic aldehydes, Malonic acid, Malononitrile, Knoevenagel condensation.

\section{INTRODUCTION}

The $\alpha, \beta$-unsaturated compounds such as cinnamic acid and ylidene malanonitriles are important reagents in organic synthesis both as intermediates and final products. They have been used to prepare compounds of biological relevance such as terahydromyricoid [1] or the antibacterial reutericyclin [2]. They are also present in some natural products, such as the juice secreted by queen honey bee [3]. They are synthesized on a commercial scale owing to their applications in food industry, polymer industry, perfume industry and technical applications. The ylidene malononitriles $(\alpha, \beta$-unsaturated nitriles) are versatile tools for production of a variety of biologically active new heterocycles [4]. Knoevenagel condensation (Doebner modification) is one of the leading methods for the synthesis of $\alpha, \beta$-unsaturated carboxylic acids and nitriles from aromatic aldehydes possessing active methylene group. The classic Knoevenagel-Doebner reaction has been carried out using high amounts of basic solvents like pyridine, $\mathrm{NaOH}$, $\mathrm{Et}_{3} \mathrm{~N}, \mathrm{CH}_{3} \mathrm{NH}_{2}$ and $\mathrm{KOH}$.

The excess amounts of these solvents damage the chemicals employed in the reaction due to their volatile nature and they are also environmentally hazardous [5]. A range of various catalysts have been used for this reaction such as ammonia, primary and secondary amines, Lewis acids, surfactants and ionic liquids [6]. In case of ultrasound [7] and microwave [8] promoted reaction it takes more time and products are purified by flash column chromatograph in which the products are obtained in less yield.

However, some of these procedures suffer from one or more limitations such as use of toxic reagents/solvents, need drastic conditions, use of expensive chemicals and relatively low yields strongly indicate the demand to develop convenient methods for classic Knoevenagel-Doebner reaction. In order to overcome these disadvantages, we used DABCO as catalyst for Knoevenagel condensation of aromatic aldehydes possessing active methylene group.

DABCO is a diazabicyclic molecule with mediumhindrance and is being widely used in organic synthesis and can serve as a weak base and ligand. DABCO has received considerable attention as an inexpensive, eco-friendly, high reactive, easy to handle and non-toxic base catalyst for various organic transformations affording the corresponding products in excellent yields with high selectivity [9].

DABCO and its analogues show high efficiency in MoritaBaylis-Hillman reactions [10] as well as cyanation of ketones [11]. It has also been employed as a catalyst for the substitution of chloropurine with alcohols [12], isothiocynation of amines, isoxazoline derivatives from activated primary nitro compounds and tertiary diamines, synthesis of naphthopyrans. Recently DABCO was used in addition of selenosulfonates to $\alpha, \beta$ unsaturated ketones and in Sonogashira coupling reaction [13]. 


\section{EXPERIMENTAL}

All chemicals were purchased from Merck or SigmaAldrich. All compounds were identified by comparison of their melting points and spectral data with those reported in the literature. Mp: Buchi-530 capillary apparatus; open capillary method and are uncorrected. IR spectra: Shimadzu IR-Affinity spectrometer, $\mathrm{KBr}$ disks; $v_{\max }, \mathrm{cm}^{-1} .{ }^{1} \mathrm{H} \mathrm{NMR} \&{ }^{13} \mathrm{C} \mathrm{NMR}$ spectra: Bruker Advance DPX $300 \mathrm{MHz}$; at $300\left({ }^{1} \mathrm{H}\right)$ and 75 $\left({ }^{13} \mathrm{C}\right)$ spectrometer in $\mathrm{CDCl}_{3}$; DMSO- $d_{6} ; \mathrm{CD}_{6} \mathrm{CO} ; \delta$ in ppm, TMS as internal standard, $J$ in Hz. Data reported in coupling constant(s) in Hertz, integration assignment]. ESI-MS: JEOL SX 102/DA-6000 mass spectrometer; in $\mathrm{m} / \mathrm{z}$.

Preparation of cinnamic acids: To aromatic aldehyde (500 mg, 1.0 equiv) and malonic acid (981 mg, 2.0 equiv) was added DABCO (105 mg, 2 equiv) in dimethyl formamide $(5 \mathrm{~mL})$ and the reaction mixture was stirred at $100-110{ }^{\circ} \mathrm{C}$ for $60-90 \mathrm{~min}$. After completion of the reaction (TLC monitoring), reaction mixture was poured in water and then extracted with ethyl acetate. Crude product was recrystallized from chloroform/hexane system to provide cinnamic acids in good yield.

Preparation of ylidene malononitriles: To the aromatic aldehyde (500 mg, 1.0 equiv) and malononitrile (291 mg, 1.2 equiv) was added DABCO (105 mg, 2 equiv) in DMF (5 mL) and the reaction mixture was stirred at room temperature for 45-60 min. After completion of the reaction (TLC monitoring) the reaction mixture was poured in water and then extracted with ethyl acetate. Crude product was recrystallized from chloroform/hexane system to provide ylidene malanonitriles in good yield.

\section{RESULTS AND DISCUSSION}

In present work, we reported a mild and efficient method for Knoevenagel condensation of aromatic aldehydes with active methylene compounds catalyzed by DABCO. Using malonic acid and malononitriles as substrates, the reaction resulted the formation of substituted trans-cinnamic acids (Scheme-I) and ylidene malononitriles (Scheme-II), respectively.

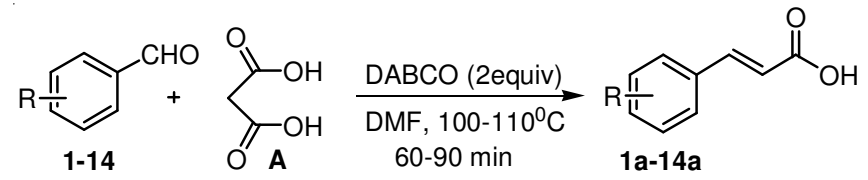
Scheme-I: DABCO-catalyzed synthesis of cinnamic acids

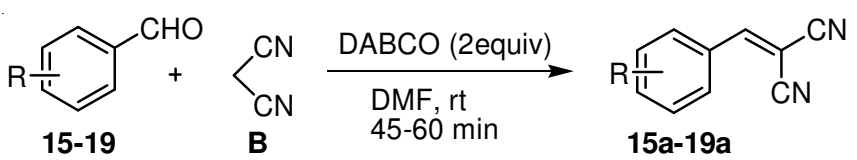

Scheme-II: DABCO-catalyzed synthesis of ylidene malanonitriles

Our preliminary studies were focused on the reaction conditions for the synthesis of trans-cinnamic acids and ylidene malanonitriles. In case of malonic acid the reaction performed at room temperature took 22-24 h for the completion of the reaction. Whereas, at refluxing conditions it took only 60-90 min for the completion of the reaction (Table-1). These results were monitored by TLC and complete disappearance of starting material was observed. In case of malononitrile stirring at room temperature gave the desired products within 45-60 min, which was also monitored by TLC and complete disappearance of starting material was observed (Table-2).

TABLE-1

KNOEVENAGEL CONDENSATION OF SUBSTITUTED AROMATIC ALDEHYDES WITH MALONIC ACID PROMOTED BY DABCO

\begin{tabular}{|c|c|c|c|c|}
\hline Entry & Substrate & Product & Time (min) & Yield (\%) \\
\hline 1 & 1 & 1a & 80 & 95 \\
\hline 2 & 2 & $2 \mathbf{a}$ & 75 & 93 \\
\hline 3 & 3 & 3a & 80 & 98 \\
\hline 4 & 4 & & 80 & 97 \\
\hline 5 & 5 & $5 \mathbf{a}$ & 70 & 98 \\
\hline
\end{tabular}




\begin{tabular}{|c|c|c|c|c|}
\hline Entry & Substrate & Product & Time (min) & Yield (\%) \\
\hline 6 & 6 & $6 a$ & 75 & 95 \\
\hline 7 & 7 & $7 \mathbf{a}$ & 90 & 85 \\
\hline 8 & 8 & 8a & 70 & 96 \\
\hline 9 & 9 & $\begin{array}{l}\mathrm{H}_{3} \\
9 \mathrm{a}\end{array}$ & 75 & 96 \\
\hline 10 & 10 & $10 \mathrm{a}$ & 78 & 91 \\
\hline 11 & $\begin{array}{c}\text { OC } \\
11\end{array}$ & 11a & 80 & 92 \\
\hline 12 & $\begin{array}{l}\mathrm{OCH}_{3} \\
12\end{array}$ & $\begin{array}{l}\mathrm{CH}_{3} \\
12 \mathbf{a}\end{array}$ & 78 & 92 \\
\hline 13 & $\begin{array}{l}\text { ocr } \\
13\end{array}$ & $\begin{array}{r}\mathrm{OCH}_{3} \\
13 \mathbf{a}\end{array}$ & 82 & 94 \\
\hline 14 & 14 & $14 a$ & 76 & 96 \\
\hline
\end{tabular}

To choose the appropriate solvent for the reaction, we examined the condensation of benzaldehyde (entry 1 ) with malonic acid (A) or malononitrile (B) in the presence of DABCO in different solvents such as dioxane, tetrahydrofuran, acetonitrile and DMF. It was observed that the high yield of products was obtained at lower reaction times in DMF solvent than in other solvents. On the basis of these results we confirm that DMF solvent is the best solvent for the Knoevenagel-Doebner reaction catalyzed by DABCO. These results are presented in Table- 3 .

\section{Conclusion}

We have demonstrated a practical application of DABCO catalyzed Knoevenagel condensation reactions, in which even hydroxy aldehydes can undergo the desired condensation with nearly quantitative yield. In addition, the notable advantages of this procedure are: (a) no need of neutralization; (b) no need of further purification. The reactions are conducted under mild conditions to afford substituted cinnamic acids and ylidene malanonitriles in good to excellent yields. 
TABLE-2

KNOEVENAGEL CONDENSATION OF SUBSTITUTED AROMATIC ALDEHYDES WITH MALONONITRILES PROMOTED BY DABCO

Entry

TABLE-3

SOLVENT EFFECTS ON KNOEVENAGEL CONDENSATION OF AROMATIC ALDEHYDES WITH ACTIVE METHYLENE COMPOUNDS CATALYZED BY DABCO

\begin{tabular}{cccc|cc}
\hline \multirow{2}{*}{ Entry } & \multirow{2}{*}{ Solvent } & \multicolumn{2}{c|}{ trans-Cinnamic acids } & \multicolumn{2}{c}{ Ylidene malononitriles } \\
\cline { 3 - 6 } & & Time $(\mathrm{h})$ & Yield $(\%)$ & Time $(\mathrm{h})$ & Yield $(\%)$ \\
\hline 1 & Dioxane & 3.00 & 92 & 1.00 & 90 \\
2 & $\mathrm{THF}$ & 3.00 & 89 & 1.20 & 85 \\
3 & $\mathrm{CH}_{3} \mathrm{CN}$ & 3.00 & 86 & 1.00 & 90 \\
4 & $\mathrm{DMF}$ & 1.33 & 97 & 0.45 & 92 \\
\hline
\end{tabular}

\section{ACKNOWLEDGEMENTS}

The authors are thankful to Council of Scientific \& Industrial Research (02 (0197)/14/EMR-II), New Delhi, India for its financial support. The authors also like to acknowledge DST (Department of Science and Technology), India in the form of INSPIRE Faculty award, (IFA13-ENG-70) and India-Korea joint project (INT/Korea/P-27).

\section{REFERENCES}

1. J. Song and M. Hesse, Tetrahedron, 49, 6797 (1993); https://doi.org/10.1016/S0040-4020(01)80423-3.
2. U. Marquardt, D. Schmid and G. Jung, Synlett, 8, 1131 (2000); https://doi.org/10.1055/s-002-411.

3. R.K. Callow and N.C. Johnston, Bee World, 41, 152 (1960); https://doi.org/10.1080/0005772X.1960.11096785.

4. T. Sasaki, K. Minamoto, T. Suzuki and S. Yamashita, Tetrahedron, 36, 865 (1980);

https://doi.org/10.1016/0040-4020(80)80036-6.

5. Y. Peng and G. Song, Green Chem., 5, 704 (2003); https://doi.org/10.1039/B310388A.

6. E. knovenagel, Ber., 31, 2596 and 2619 (1898). https://doi.org/10.1002/cber.18980310308.

7. J. Mc Nulty, J.A. Steere and S. Wolf, Tetrahedron Lett., 39, 8013 (1998); https://doi.org/10.1016/S0040-4039(98)01789-4.

8. P.S. Kwon, Y.M. Kim, C.J. Kang, T.W. Kwon, S.-K. Chung and Y.-T. Chang, Synth. Commun., 27, 4091 (1997); https://doi.org/10.1080/00397919708005456.

9. Y. Peng and G. Song, Green Chem., 5, 704 (2003); https://doi.org/10.1039/B310388A.

10. S.-K. Tian, R. Hong and L. Deng, J. Am. Chem. Soc., 125, 9900 (2003); https://doi.org/10.1021/ja036222p.

11. D. Basavaiah, A.J. Rao and T. Satyanarayana, Chem. Rev., 103, 811 (2003); https://doi.org/10.1021/cr010043d.

12. S.K. Tian, R. Hong and L. Deng, J. Am. Chem. Soc., 125, 9900 (2003); https://doi.org/10.1021/ja036222p.

13. J.A. Linn, E.W. McLean and J.L. Kelley, J. Chem. Soc. Chem. Commun., 913 (1994);

https://doi.org/10.1039/C39940000913. 